Article

\title{
Daylighting Design in Classroom Based on Yearly-Graphic Analysis
}

\author{
Yang Guan ${ }^{1,2,3}$ and Yonghong Yan 1,2,3,* \\ 1 Faculty of Architecture and Urban Planning, Chongqing University, Chongqing 400044, China; \\ 20111501004c@cqu.edu.cn \\ 2 State Key Lab of Subtropical Building Science, South China University of Technology, \\ Guangzhou 510640, China \\ 3 Key Lab of Ministry of Education for New Technology of Mountainous Towns, Chongqing 400044, China \\ * Correspondence: y65127803@126.com; Tel.: +86-23-6512-7803
}

Academic Editor: Chi-Ming Lai

Received: 2 May 2016; Accepted: 22 June 2016; Published: 11 July 2016

\begin{abstract}
In China, existing buildings comprise more than 40 billion square meters, most being of high energy consumption. A substantial reduction in electrical energy costs could be obtained through greater use of daylight. Daylight varies widely due to the movement of sun, changing seasons and diverse weather conditions. Custom static daylight assessments, simulations represent only one time of the year or one time of the day, are inadequate to evaluate the dynamics of daylight variability. Using the intuitive graphic tool Temporal Map to display the annual daylight data, this study compared different passive architectural design strategies under the climate conditions of five representative Chinese cities and selected the most suitable design scheme for each city. In this study, the dynamic yearly-graphic tool was utilized for architectural design in China, and we integrated the optimal design with the Chinese academic calendar to achieve improvements within the occupancy time. This modified map connects design work with human activity that makes daylight evaluation more accurate and efficient. The results of this study will provide preliminary recommendations for energy-saving design in China, and reference to other similar studies.
\end{abstract}

Keywords: daylighting design; graphic analysis; temporal map; occupancy time

\section{Introduction}

With the serious environmental deterioration and global energy crisis, increased attention has been paid to the current trends in energy consumption. The international demand for oil, coal and natural gas are expected to increase by 30\%-50\% from 2007-2035 [1] while the energy-related emissions of $\mathrm{CO}_{2}$ will double by 2050 [2]. As buildings account for more than $40 \%$ of the total energy in some developed countries with a related emission of $40 \%$ of total GHG emissions [3,4], energy-saving in buildings has attracted more and more attention worldwide. Daylight, as one of the inexhaustible natural resources, is valuable because its proper use can save electrical energy consumption $[5,6]$, be beneficial to human health $[7,8]$ and improve work performance $[9,10]$. Accordingly, it is always necessary to achieve an effective daylighting design for better lighting quality and low energy cost.

A comparative research was undertaken among United States (US), the European Union (EU), and the BRIC (Brazil, Russia, India and China) countries as these countries are responsible for more than $60 \%$ of energy consumption worldwide. The results showed that China is the country with the largest energy consumption globally, with a rate of 18\% in 2010; the US and EU followed behind, taking up $17 \%$ and $13 \%$ respectively in the same year [11]. According to the latest Chinese government reports, there are now more than 40,000,000,000 $\mathrm{m}^{2}$ of building space in China [12], most of which have a high energy-consumption profile [13]. In 2013, the energy consumed by buildings, artificial lighting 
being a main constituent, accounted for $19.7 \%$ of the national annual usage of energy [13]. In addition, the prevalence rate of myopia is extremely high in Chinese youth according to current government statistics [14]: up to $40.89 \%, 67.33 \%$ and $79.2 \%$ in primary, junior and high school respectively , and remarkably, $84.72 \%$ in university. Indeed, the database, derived from the national survey of adolescent health, conducted every five years, shows that the myopia rates have steadily climbed in recent decades [14-16]. Meanwhile, it has been proven that elevated light levels have preventive effect on myopia $[17,18]$. Given the potential of energy savings and health benefits to students, the improvement of light quality in such environments is a priority issue.

China is a vast country 9.6 million square kilometers in size. Defined by Chinese standard for daylighting design of buildings [19], according to the meteorological monitoring data, there are five light-climate regions numbered from 1 to 5 , where the higher number indicates less natural light resources. Because climate characteristics by region are so diverse, it is difficult to create standard recommendations across the whole country. The objective of this paper is to investigate the proper daylighting design of a typical south-facing classroom under different climate conditions of five representative cities. From the perspective of the whole country, we study the design of how to respond to climate variety and guarantee the quality of indoor lighting.

It is key to adopt a proper assessment method for daylight performance in the design process. The current means of daylight assessment in China is mainly by static metrics. The Chinese standards for daylighting design only regulate some custom parameters, such as daylight factor, illuminance threshold values and so on [19]. Reports on classroom daylight performance in different Chinese areas have seldom considered the annual diversity [20-22]. Daylight varies due to time-dependent environmental factors such as the movement of sun, changing seasons and diverse weather conditions. The static daylight metrics of one moment, such as daylight factor is hardly representative of changes in light levels throughout the year. Nowadays, the most widely used dynamic daylight metrics are Daylight Autonomy(DA) [23,24] which is defined as the percentage of annual work hours where daylight is sufficient to exceed a benchmark illuminance and Useful Daylight Illuminance (UDI) [25] which is similar to DA except that the benchmark is replaced by the illuminance range 100 to $2000 \mathrm{~lx}$. Due to the advantage of dynamic daylight parameters that make consideration of daylight annual performance, DA and UDI are utilized continually and widely in daylight assessment and relative design process in recent years [26-28].

There are also some applications of dynamic daylight assessment in China. U.Berardi and Taoning.Wang designed an atrium-type high performance house to participate in the first Solar Decathlon Competition in China, held in the city of Datong in August 2013. Ecotect, Radiance, DIVA, and Daysim were used to simulate the daylight throughout the year considering weather of Datong and Worcester, Massachusetts(US). Results of daylight simulations have allowed evaluating extensively parameters such as Daylight Factor, Daylight Autonomy, and Useful Daylight Index. Moreover, this research has studied the problem of visual comfort inside the house with large areas of glazed openings [28]. Gou Zhonghua and Liu Shaoyu evaluated the performance of Anidolic lighting technique for the first floor inhabitant in Hong Kong with high-rise and high-density surroundings. Through comparison of Daylight Autonomy, calculated by Daysim, for different design strategies, the Anidolic system was tentatively confirmed to be obviously superior with higher DA score and be helpful to energy-saving [29]. Sun Chanjuan and Lian Zhiwei advocated an evaluation method on luminous environments and energy consumption for commercial building with computer simulation by Daysim and TRNSYS [30].

Actually, some recent research begins to focus on the intuitive graphic expression of computer-based analysis techniques which can enhance its applicability in the design work of daylit space. Christoph F. Reinhart studied how simulation results for a sidelit space can be visually presented to simulation non-experts using the concept of a daylighting dashboard [31]. Marilyne Andercen developed the temporal map to display annual daylight data on a surface map whose axes represent the hours of the day and the days of the year [32]. His research group pointed out the limitation 
of existing time-based metrics, like DA (Daylight Autonomy) [23,24] and UDI (Useful Daylight Illuminance) [25] that do reflect the proportion of annual work hours that achieve an illuminance benchmark or acceptable range while do not account for which times or areas that illuminance does not meet the recording threshold. In other words, DA can show that for 70 percent of annual working hours, a particular point has adequate daylight, but it cannot show whether this point is underperforming in the morning hours, or in the winter [33]. The team of Andercen developed synthesis analysis tools, Lightsolve, to overcome this issue [32-34]. Lightsolve does annual daylghting calculation with the ASRC-CIE sky model and displays yearly data on a temporal map that a color-scaled surface graph with the year on the $x$-axis and the day on the $y$-axis. This retains the temporal variability of performance in a very dense format.

In this paper, the expression way of Lightsolve, temporal map, was adopted to display the annual data calculated by Daysim. The regular temporal map was integrated with the Chinese academic calendar to make the analysis more accurate and efficient. Time segments of yearly holidays and daily lunch break were marked on the axis of the temporal maps to remind the designer to focus on the data within occupancy time. Comparison of several design strategies, through this modified temporal map, produced preliminary advice about daylighting design for the five representative cities. The results and analysis method can also be used as reference for the optimal daylighting design in other Chinese cities.

\section{City selection}

As mentioned above, there are five light-climate regions in China. In order to compare climate-related differences, five cities were selected from each light-climate region: Lhasa (Region I), Yinchuan (Region II), Beijing (Region III), Shanghai (Region IV) and Chongqing (Region V) (Figure 1). Each of these cities is the capital of its province and has a population in the millions. The map of the division of the light-climate regions in China with the five representative cities indicated is shown in Figure 1 while these cities' geographical information is listed in Table 1.

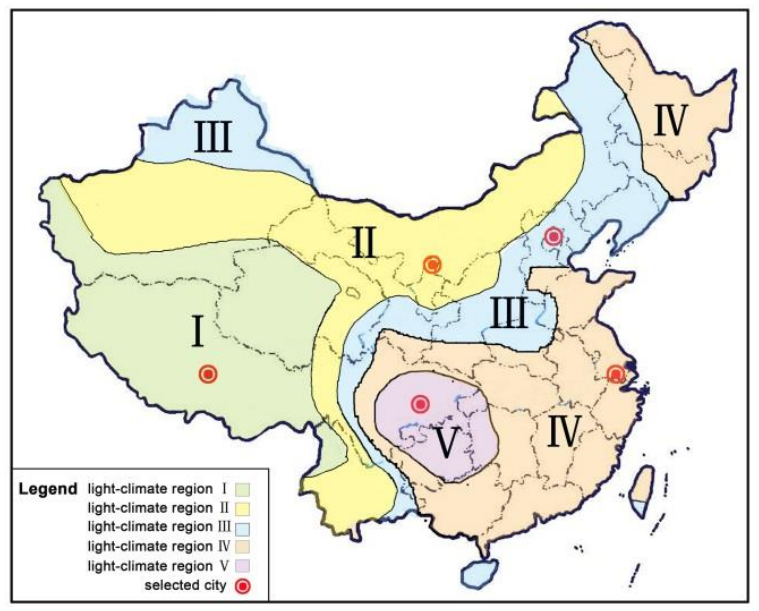

Figure 1. Light climate regions in China.

Table 1. Geographical information of five representative cities.

\begin{tabular}{ccc}
\hline & Longitude & Latitude \\
\hline Lhasa & $91.13^{\circ} \mathrm{E}$ & $29.67^{\circ} \mathrm{N}$ \\
Yinchuan & $106.2^{\circ} \mathrm{E}$ & $38.47^{\circ} \mathrm{N}$ \\
Beijing & $116.28^{\circ} \mathrm{E}$ & $39.93^{\circ} \mathrm{N}$ \\
Shanghai & $121.47^{\circ} \mathrm{E}$ & $31.40^{\circ} \mathrm{N}$ \\
Chongqing & $106.47^{\circ} \mathrm{E}$ & $29.58^{\circ} \mathrm{N}$ \\
\hline
\end{tabular}


Temporal maps of the five cities were drawn with the exterior annual horizontal illuminances calculated by Daysim in five-minute intervals. The annual data were presented on surface maps, in which the hours of the day are shown in the vertical axis and the days of the year are shown in the horizontal axis. As shown in Figure 2, these maps are quite different under the same color bar of illuminance set from 0 to $10 \times 10^{4} \mathrm{~lx}$, corresponding to the colors from blue to red. Maps of Lhasa, Yinchuan and Beijing (Region I, II and III) were redder in color, indicating higher levels of solar illuminance, while the maps of Shanghai and Chongqing (region IV and V) were bluer, meaning lower daylight intensity.
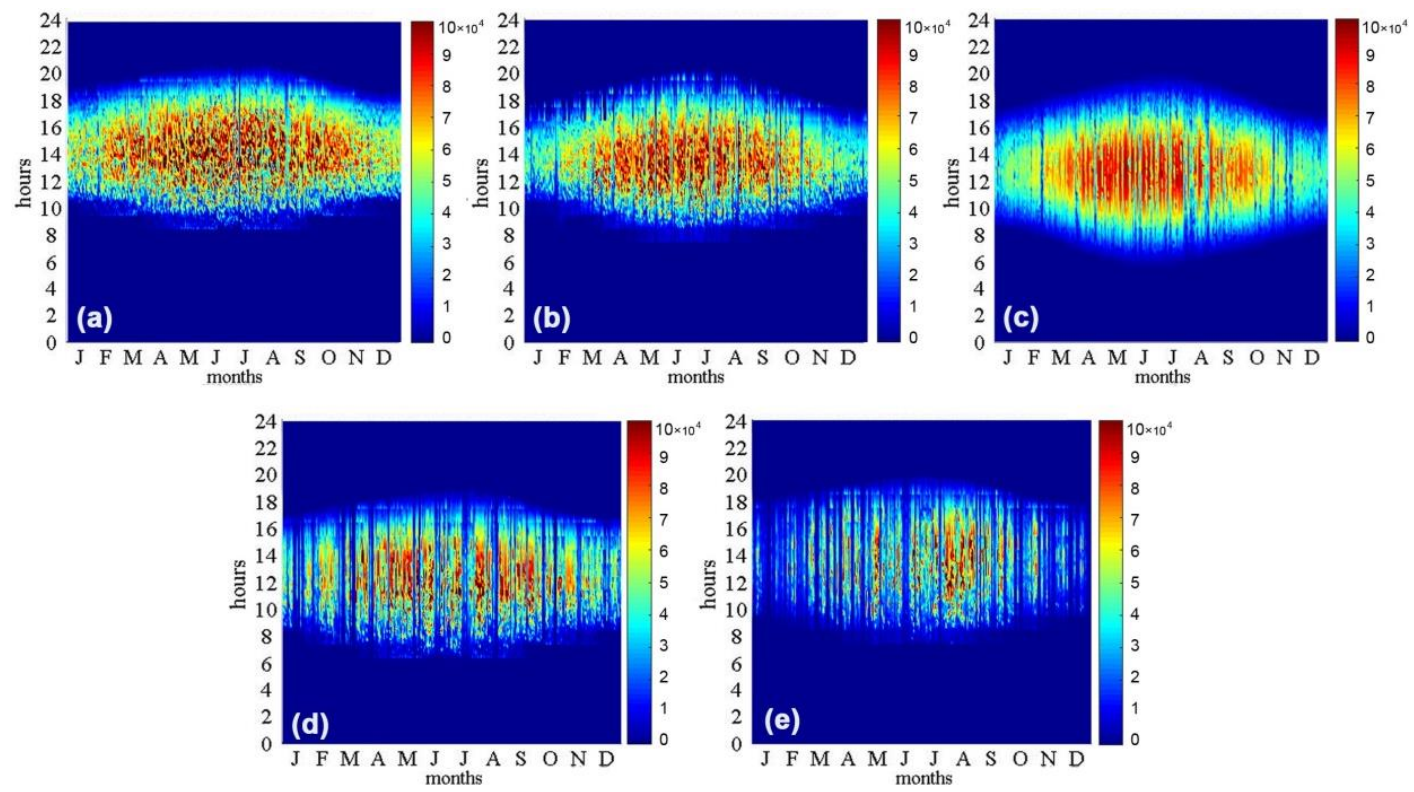

Figure 2. Temporal maps of annual exterior illuminance:

(a) Lhasa;

(b) Yinchuan;

(c) Beijing;

(d) Shanghai; and (e) Chongqing.

We also established a numerical analysis in addition to the graphical representation. The frequency of four standard CIE skies in each city, were calculated using the ASRC-CIE sky model developed by Perez [35] combined with Hourly Typical Meteorological Year (TMY2) data [36]. In the calculation process, the frequencies of four skies were dependent on the sky clearness $\varepsilon$ and brightness $\Delta$, which were calculated using the horizontal diffuse irradiance, the normal incident irradiance and the solar zenith angle [35]. As shown in Table 2, there were more clear skies in cities in lower light-climate region number, and more overcast skies in cities in higher light-climate region number. The differences in the proportion of clear and overcast skies were quite obvious. Lhasa and Chongqing were the two extremes: Lhasa had clear skies more than half of the year, specifically, $62.33 \%$ (clear sky of $19.39 \%$ plus clear turbid sky of $42.94 \%$ ), while overcast skies in Chongqing reached $73.55 \%$, accounting for nearly three quarters of a year. In comparison, the annual frequency of clear skies in Lhasa (62.33\%) was over 10 times that of Chongqing (4.66\%), while the frequency of overcast skies in Chongqing (73.55\%) was about 10 times that of Lhasa $(7.21 \%)$.

Table 2. Annual frequency of four CIE (Commission Internationale de L'Eclairage) standard skies.

\begin{tabular}{ccccc}
\hline & Clear & Clear Turbid & Intermediate & Overcast \\
\hline Lhasa & $19.39 \%$ & $42.94 \%$ & $30.46 \%$ & $7.21 \%$ \\
Yinchuan & $12.27 \%$ & $37.29 \%$ & $34.87 \%$ & $15.58 \%$ \\
Beijing & $7.07 \%$ & $29.38 \%$ & $33.98 \%$ & $29.56 \%$ \\
Shanghai & $2.91 \%$ & $17.76 \%$ & $35.72 \%$ & $43.61 \%$ \\
Chongqing & $0.28 \%$ & $4.38 \%$ & $21.80 \%$ & $73.55 \%$ \\
\hline
\end{tabular}


The intuitive graphical and detailed numerical analysis above revealed the complexity of the Chinese climate, and also illustrated the necessity for full consideration of daylight characteristics in the design process. Further analysis on the indoor daylighting feature and comparison of different passive design strategies will be discussed in the following sections.

\section{Method}

In Section 2, the drawn conclusion was that annual exterior illuminance differs greatly in different light-climate regions. Next, this study will investigate the indoor daylighting quality and discuss the most suitable design strategies in response to various climate characteristics in the 5 light-climate regions.

\subsection{Typical Classroom}

A typical south-facing classroom was chosen as a base case for daylight assessment and optimal design. This classroom is quite normal in China with a size of $66.5 \mathrm{~m}^{2}$ and $3.2 \mathrm{~m}$ ceiling, and a window to wall ratio of 0.21 . The daylighting conditions of the typical classroom with several design strategies were evaluated by computer simulation during the course of a year. Analysis and optimization were carried using the validated daylight software Daysim over a grid with $0.5 \mathrm{~m}$ spacing positioned at work plane height. Temporal maps, with hours of the day on vertical axis and days of the year on horizontal axis, were drawn with Daysim results for overall understanding of the variation of annual data. The performance goal of this classroom was to advance conditions that were bright enough within the academic occupancy time using daylight alone. The plan of the classroom is shown in Figure 3 and the reflectance of interior materials is presented in Table 3. The transmittance of double-pane window with clear glass is $78.2 \%$.The radiance simulation parameters were set as follow: -ab 3 -aa 0.15 - ar 128 -ad 512 -as 128; and simulation time step was one hour.

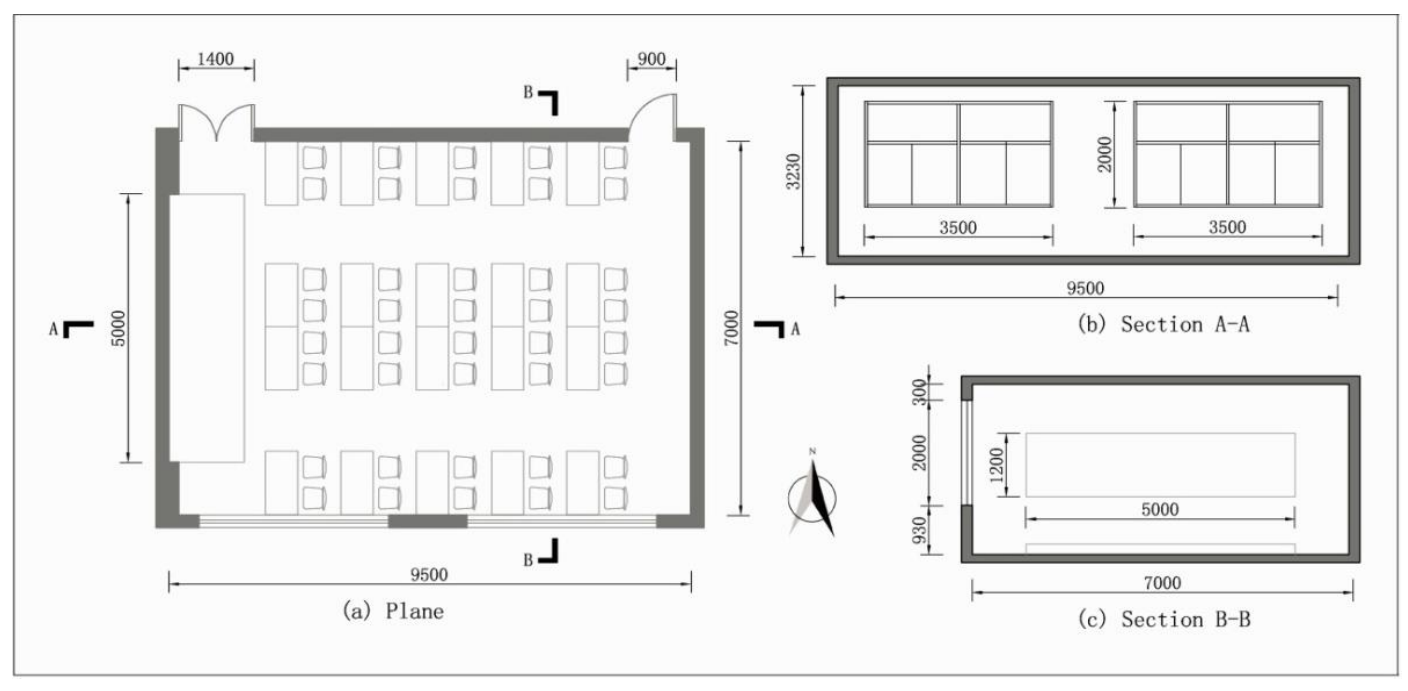

Figure 3. Plane and sections of the typical classroom: (a) plane; (b) section A-A; and (c) section B-B.

Table 3. Reflectance value of interior surfaces.

\begin{tabular}{cc}
\hline Surface & Reflectance (\%) \\
\hline Wall & 78.3 \\
Ceiling & 59.5 \\
Floor & 36.7 \\
Wood door & 28.5 \\
Blackboard & 12.76 \\
Desktop & 13.8 \\
\hline
\end{tabular}




\subsection{Goal Oriented Metrics}

When one performs daylighting analysis, it is implicitly or explicitly to test the extent to which a design scheme meets one's expectations or performance objectives. The goal-oriented metrics, which display the percentage of an area of interest that stays within a chosen illuminance range, was applied to compare the daylighting performance of different design strategies. These metrics, first proposed by Kleindienst [37], would show how closely the objective defined by the designer is fulfilled rather than express absolute performance values. $\mathrm{UDI}_{450-20001 \mathrm{x}}$ is set as the benchmark for lighting assessment in this paper. The concept of Useful Daylight Illuminance was first proposed by Mardaljevic in 2005 [38], initially requiring upper and lower thresholds of 100 and 2000 lx respectively. Subsequently, it has been enhanced by partitioning the $\mathrm{UDI}_{100-2000}$ range into 100-500 lx and 500-2000 lx, called UDI-supplementary and UDI-autonomous respectively $[39,40]$. For the range of UDI-supplementary, additional artificial lighting may be needed to supplement the daylight for common tasks such as reading; while the UDI-autonomous means additional artificial lighting will most likely not be needed. As this paper focuses on building energy conservation, the index of UDI-autonomous was selected for lighting analysis. The higher the ratio of spatial area that meets the desired range, the less artificial lighting is needed, thus achieving better energy saving effects. Daylight standards in China require that the desktop horizontal illuminance in the classroom provided by natural light should not be below 450 lx [19], but no upper limit regulation exists. Accordingly, the desired illuminance of 450 to $2000 \mathrm{~lx}$ was chosen in this study. However, it should be observed that Mardaljevic revised the autonomous range into $\mathrm{UDI}_{300-30001 x}$ in some later papers [41,42]. While the initial UDI range of 100-2000 lx was based on multiple surveys on human preference and performance, it is accepted and applied more widely in relative studies $[28,43,44]$.

For the benchmark of 450-2000 lx in this paper, there are at most three possible outcomes excessive, within or below the desired range. Therefore, at every design condition, three temporal maps were created: one displayed the percentage of the work plane in $0.5 \mathrm{~m}$ grid that was within the desired illuminance range, another map displayed the percentage of work plane that was too bright and the third showed how much of the work plane was too dark. The three types are referred to as "in range" temporal map, "too bright" temporal map and "too dark" temporal map.

\subsection{Temporal Map within the Occupancy Time}

The regular temporal maps display all of the annual data on one surface picture [33]. In the author's opinion, the designer should pay more attention to the daylighting performance in occupancy time, which would make the optimization more efficient. Take the educational architecture as an example, extreme climate conditions usually appear in the time periods of summer or winter holidays. If the occupancy time is not distinguished, a great effort may be made to improve the high risk of glare in the summer holiday and/or the daylight deficiency in the winter holiday, which inevitably results in waste. Accordingly, considering the Chinese academic schedule, this study judged the design strategies based on the daylight performance within the school occupancy time.

In China, students have three months off per year: February, July and August, and daily academic schedule is from 8:00 a.m. to 6:00 p.m. (excluding lunch break from 12:00 p.m. to 2:00 p.m.). Time segments of yearly holiday and daily lunch break were marked with dotted line on the temporal maps in this paper. The diagram of occupancy and unoccupied time is shown in Figure 4a and an example of a temporal map with occupancy time marked is shown in Figure $4 \mathrm{~b}$. The designer may ignore the marked time segments and concentrate on the daylighting information within the occupancy time. In this article, the data in unoccupied time were marked rather than deleted because in that way the integrity of the annual distribution feature can be retained and benefit the designer making an overall analysis and rational policy. 


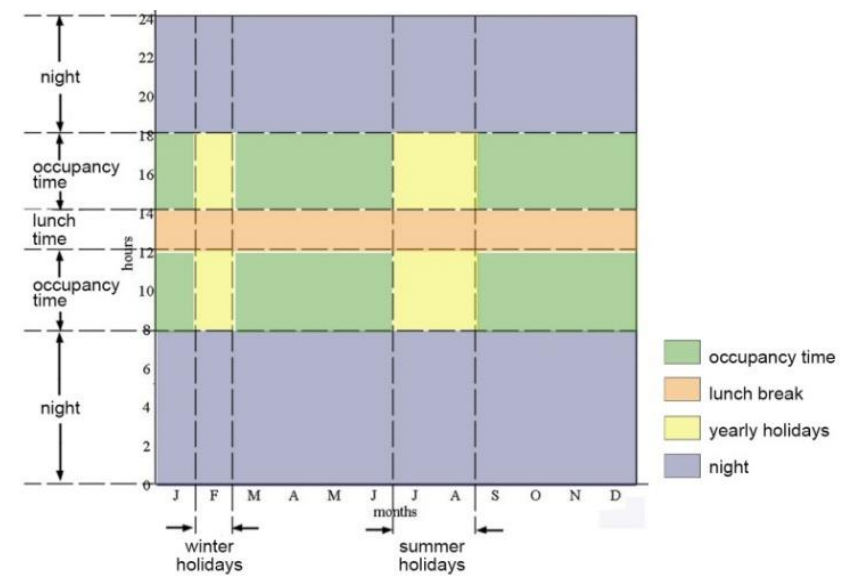

(a)

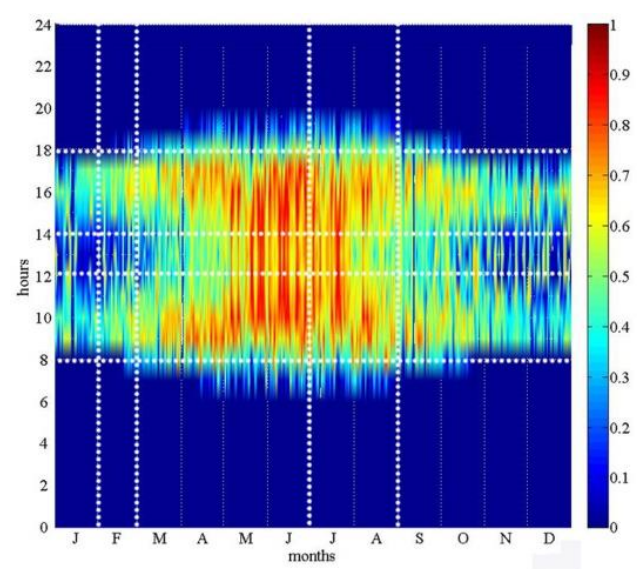

(b)

Figure 4. Diagram (a) and example (b) of temporal map with occupancy time marked.

\section{Results}

\subsection{Analysis on Interior Daylighting}

Daylighting simulations were performed by Daysim with the model of base classroom and weather files of five representative cities. The calculation results are shown in Figure 5 in form of temporal maps. The results reveal that these maps were quite different under the same color bar of the fulfilling ratio set from 0 to 1, corresponding to the colors from blue to red. In terms of the "in range" performance, maps of cities in the lower light-climate region number, such as Lhasa (Figure 5a-1) and Yinchuan (Figure 5b-1), were redder, meaning more spatial area achieved the desired illuminance range. Similarly, the "too bright" maps were also redder in these cities (Figure 5a-2,b-2), indicating higher risk of glare. However, the "too dark" maps were bluer (Figure 5a-3,b-3), showing that less spatial area were below the minimum limit. In summary, cities in the lower region number, such as Lhasa (Region I) and Yinchuan (Region II), received more daylight quantity than other cities with the same architectural feature. They score higher ratio of spatial area within desired illuminance range, face more risk of glare but lower probability of lighting deficiency.

For the cities in higher light-climate region number, the "in range" maps were less red, meaning less spatial area fulfilled the desired illuminance range. The "too bright" maps were bluer and "too dark" maps were redder than other cities, indicating lower risk of glare but higher possibility of inadequate lighting. For instance, there were some red lines on the "too dark" maps of Chongqing (Figure 5e-3) and Shanghai (Figure 5d-3), which implied that indoor lighting was below the desired range all day long. In these cities, the main issues were inadequate lighting intensity while glare control was a relatively minor problem.

Generally speaking, in the comparison of indoor daylight quality, the base classroom in cities in lower light-climate region number performed better as there was more spatial area in the desired illuminance range. The major issues of daylighting optimization are distinct in different regions and are attributed to their climate diversity. The cities rich in daylight resource (Lhasa and Yinchuan) are mainly affected by the glare risk and consequently the optimal work would emphasize the setting of architectural shading facilities. On the other hand, the cities with less daylight resource often suffer from light deficiency and at the same time also face glare risk. Daylighting optimization in these cities involves expanding window size, while being competent for glare control. Considering the distinct issues of the base classroom in different regions, the five cities were classified into two groups in the daylighting optimal work. We analyzed light shelf and several shading strategies in climate conditions of Lhasa (Region I) and Yinchuan (Region II), and compared light shelf, shading and expanding window size under climate conditions of Beijing (Region III), Shanghai (Region IV) and Chongqing 
(Region V). The design strategies compared in different light-climate regions are shown in Figure 6. From the temporal maps drawn with the annual data of different passive architectural scheme, the most suitable strategy will stand out for each of the regions with higher proportion of spatial area in the desired illuminance range.

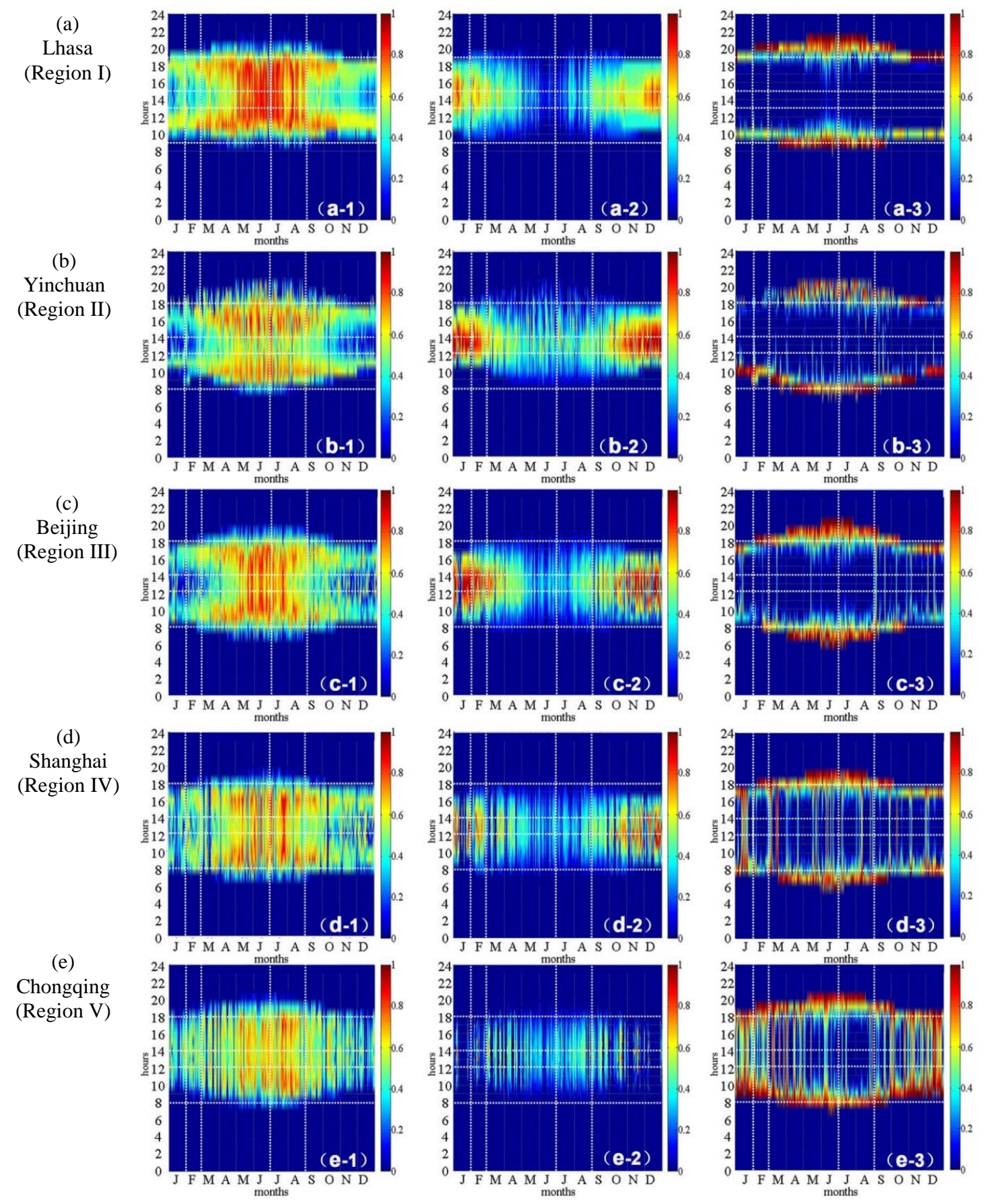

Figure 5. Temporal maps of base classroom: "in range"maps in the first column, "too bright" maps in the second column, "too dark" maps in the third column; row 1 to 5 are maps of (a) Lhasa; (b) Yinchuan; (c) Beijing; (d) Shanghai; and (e) Chongqing. 


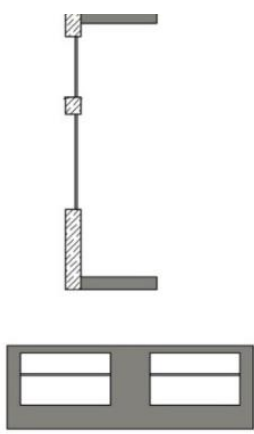

Base case

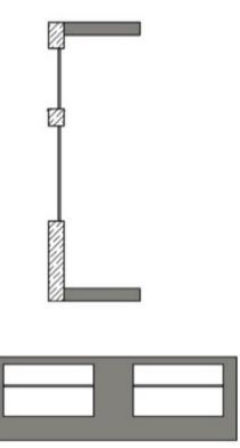

Base case
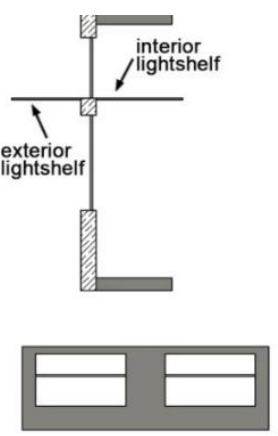

scheme a-1 light shelves

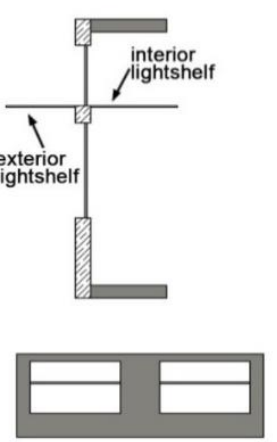

scheme b-1 light shelves

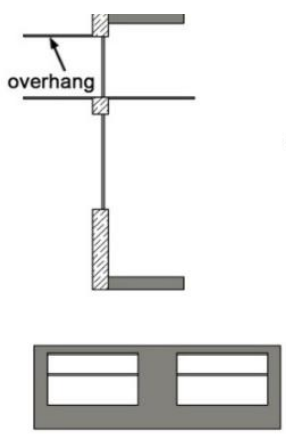

scheme a-2 light shelves+overhang

(a)

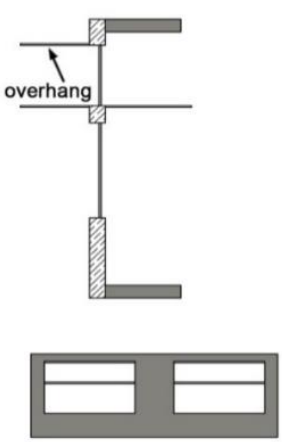

scheme b-2

light shelves+overhang

(b)

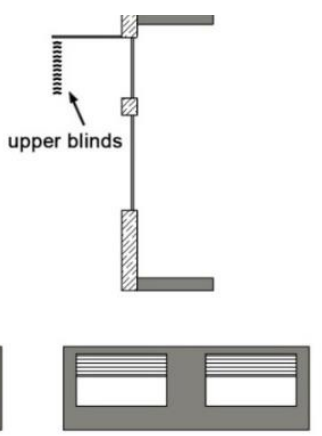

scheme a-3 overhang+upper blinds
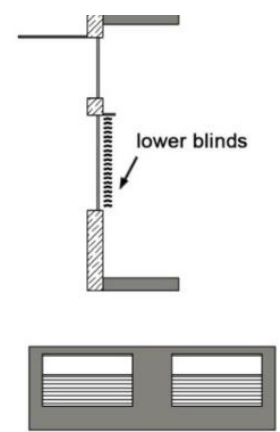

scheme a-4 overhang+lower blinds

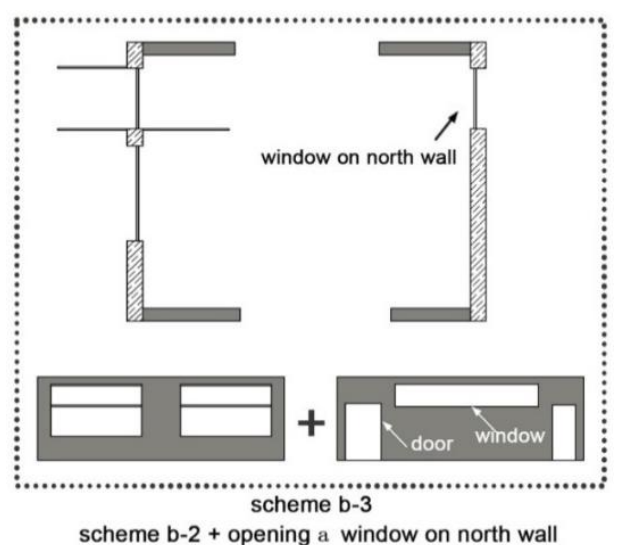

Figure 6. Daylighting strategies compared in different light-climate regions. (a) Straegies for light-climate regions 3-5; (b) Straegies for light-climate regions 3-5.

\subsection{Daylighting Design for Regions I-II}

The four passive architectural strategies and their "in range" temporal maps are shown in Figure 7. Compared to the base case, daylighting performances under the four new schemes were all improved. There were more areas in red color and less areas in blue. The scheme of "light shelves +overhang" (Scheme a-2) performed the best. Under the condition of scheme a-2, the temporal map of Yinchuan (Figure $7 \mathrm{~h}$ ) was red from March to October. It showed that nearly $80 \%$ of the spatial area achieved its daylighting objective. The situation was a little worse from November to February when the ratio of fulfillment in the acceptable range was about $50 \%$. As February is in the winter holiday in Chinese school, the scheme a-2 of "light shelves + overhang" achieved a satisfactory outcome. Specifically, those three months (from November to January) scored 50\% of spatial area reaching the daylight requirement and the rest months mostly scored $80 \%$. The low ratio of area fulfill threshold mainly occurred in the early morning and late afternoon, when the sun is near the horizon. Most regions in China adopt the Beijing Time, which is about one hour early than the solar time of Yinchuan. The temporal map showed that before 10:00 am from November to February and before 9:00 am from March to October, the daylight performance was poor and artificial lighting was needed to improve the indoor lighting quality. 


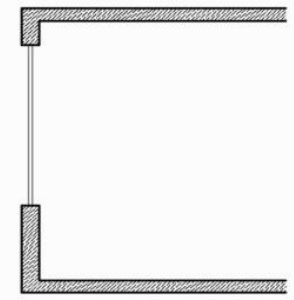

Base case

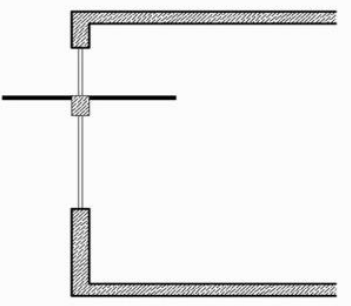

Scheme a-1 Light shelves

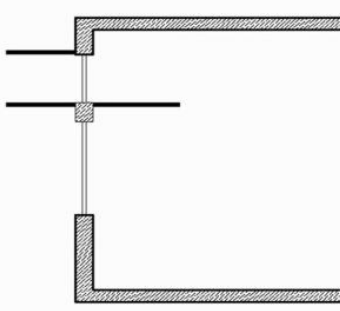

Scheme a -2 Light shelves+overhang

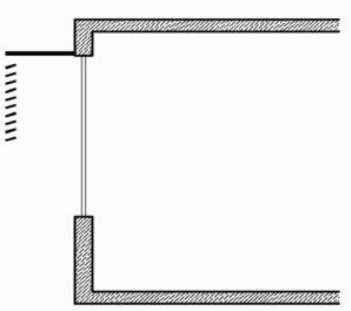

Scheme a-3 overhang+upper blinds

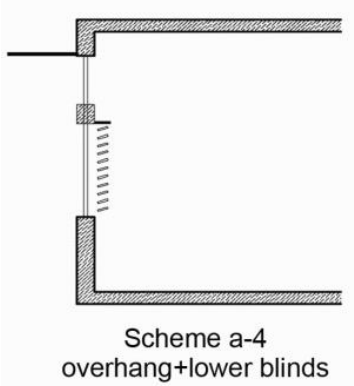

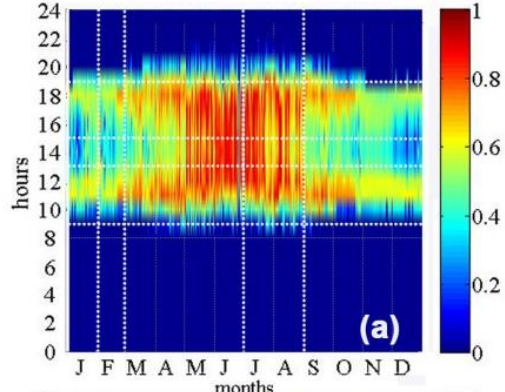
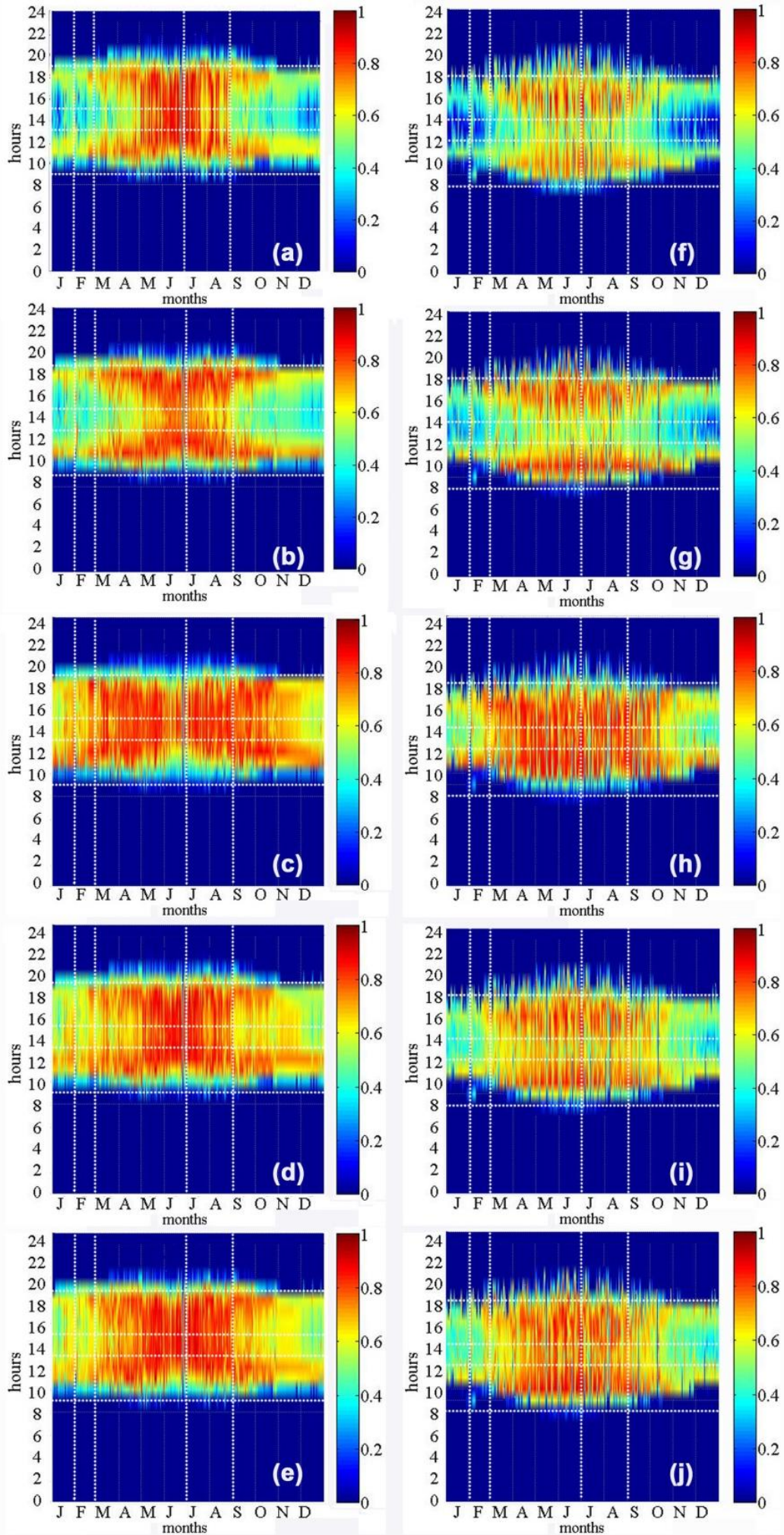

Figure 7. "In range" temporal maps of base classroom $(\mathbf{a}, \mathbf{f})$ and different strategies in Lhasa $(\mathbf{b}-\mathbf{e})$ and Yinchuan $(\mathbf{g}-\mathbf{j})$.

Being similar to Yinchuan, the scheme a-2 of "light shelf +overhang" performed best under the climate condition of Lhasa. The "in range" map (Figure 7c) was reddest in scheme a-2, implying that more area was in range than with the other schemes. The proportion of area that achieved the 
daylighting objective reached $80 \%$ from March to October and about $60 \%$ from November to February. However, there was still the same problem of lighting deficiency in early morning and late afternoon. Lhasa adopts Beijing Time, but the school daily schedule is one hour later than normal due to the longer time difference between Lhasa's solar time and the Beijing Time. Judging from the daylight in occupancy time, it can be seen that the time segments from 9:00 a.m. to 10:00 a.m. and 6:00 p.m. to 7:00 p.m. need extra artificial lighting to improve the low lighting intensity.

Besides the high ratio of area researching illuminance threshold, the uniform distribution of daylight is equally important to the quality of indoor environment. An ideal lighting environment should provide better illumination distribution and increase the homogeneity of daylight into the space [45]. Therefore, we added the analysis of $\mathrm{UDI}_{450-20001 x}$ at different distances from the window for base case and the optimal architectural strategies. As shown in Figure 8a,b, comparing to base case, four passive designs all decrease the $\mathrm{UDI}_{450-20001 x}$ levels in the first few meters in front of the window while enhance the daylighting in back of the room. The maximum level of $\mathrm{UDI}_{450-20001 \mathrm{x}}$ occurs at $2 \mathrm{~m}$, $4 \mathrm{~m}, 3 \mathrm{~m}$ and $3 \mathrm{~m}$ away from windows for scheme a- 1 to a- 4 respectively. It can be seen that the scheme a-2 allows a more homogenous distribution than other schemes, especially enhances the UDI $450-20001 x$ levels far away from the window.

In summary, the "in range" temporal map of scheme a-2 appears reddest and its curve of average $\mathrm{UDI}_{450-20001 \mathrm{x}}$ for equal distances from the window presents most smooth. That is to say the most suitable strategy for Lhasa and Yinchuan is the same scheme a-2 of "light shelves +overhang", in which the overhang declines glare risk and the light shelves make lighting more uniform. "In range" temporal maps showed that the proportion of spatial area achieved desired illuminance range, which was higher from March to October, about $80 \%$, and lower, but still good, from November to February, about $50 \%$ to $60 \%$. However, the ratio values were very low in the early morning and late afternoon, which was attributed to the sun movements when it is near to the horizon. Thus supplementary artificial lighting is needed in the time segments of the first and last lessons of the day.

\subsection{Daylighting Design for Regions III-V}

Different from the region I-II, the scheme b-2 of "light shelves +overhang" performed unsatisfactory under the climate conditions in regions III-V. After opening a window on the north wall, daylighting quality was obviously improved in all the three cities, as shown in Figure $9 \mathrm{~d}, \mathrm{~h}, \mathrm{l}$. Under the optimal scheme b-3, the proportion of the spatial area that met the illuminance range reached $80 \%$ from March to October, and 50\% from November to February. These cities also need extra artificial lighting in early morning and late afternoon. 


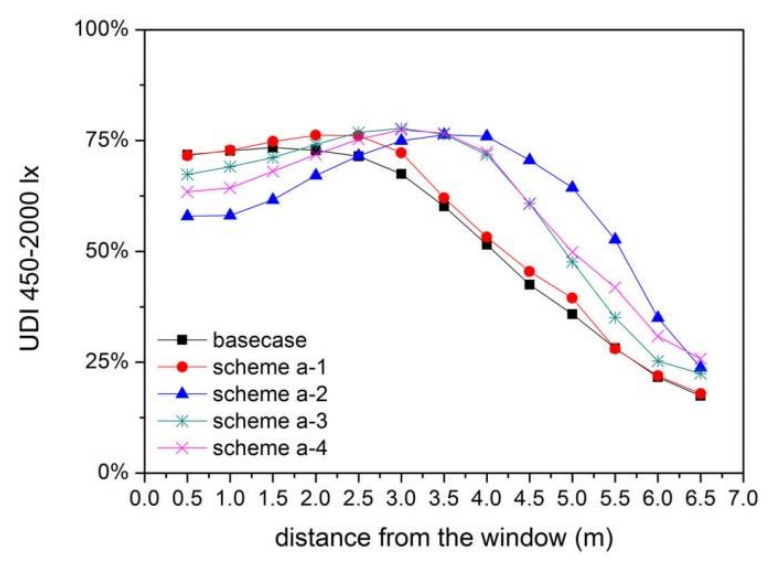

(a)

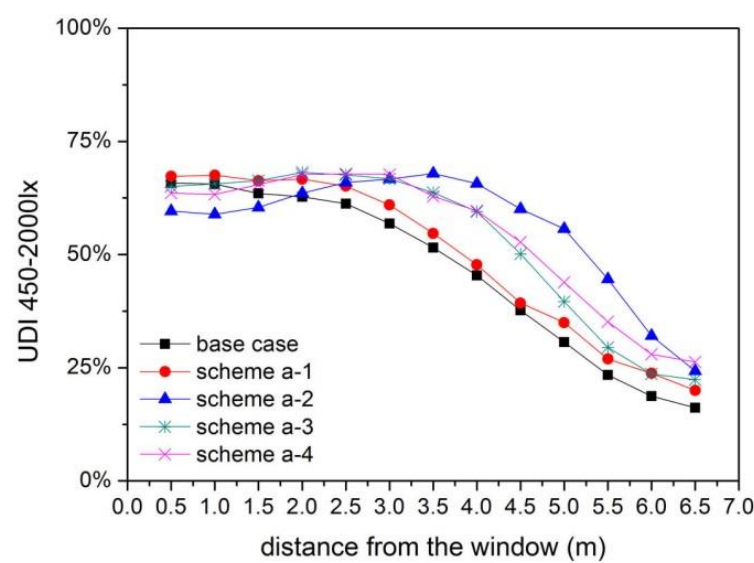

(b)

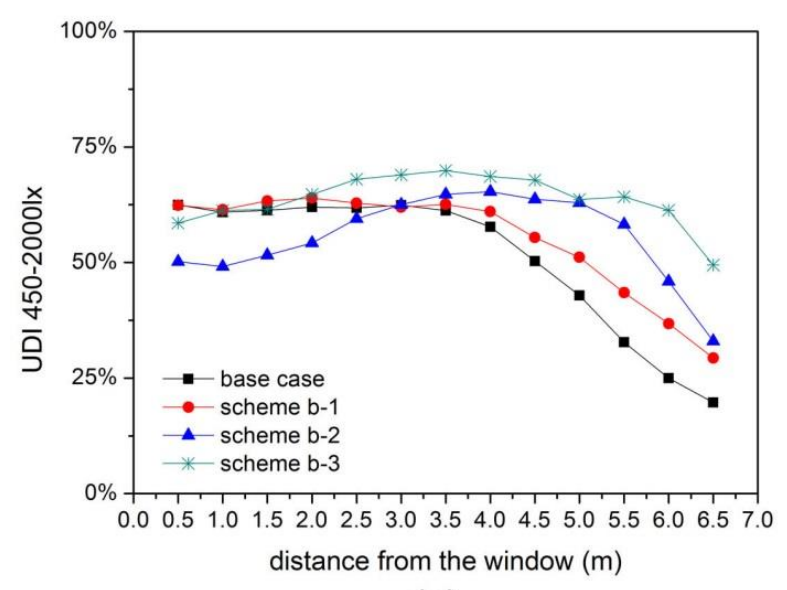

(c)

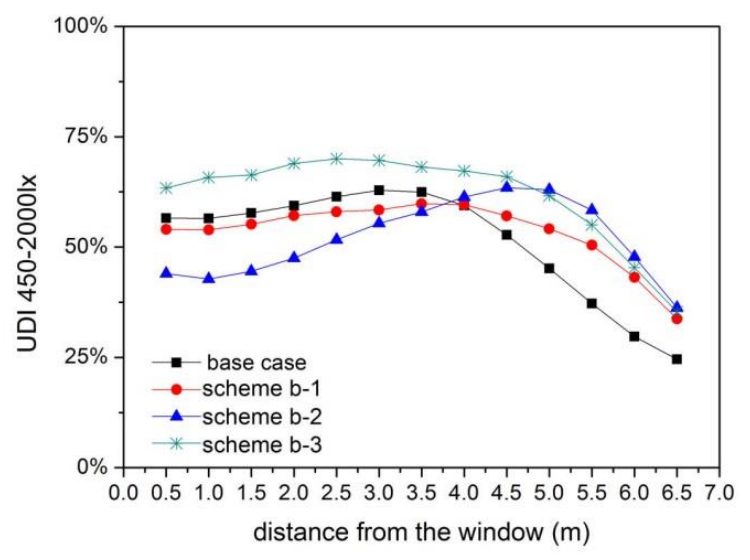

(d)

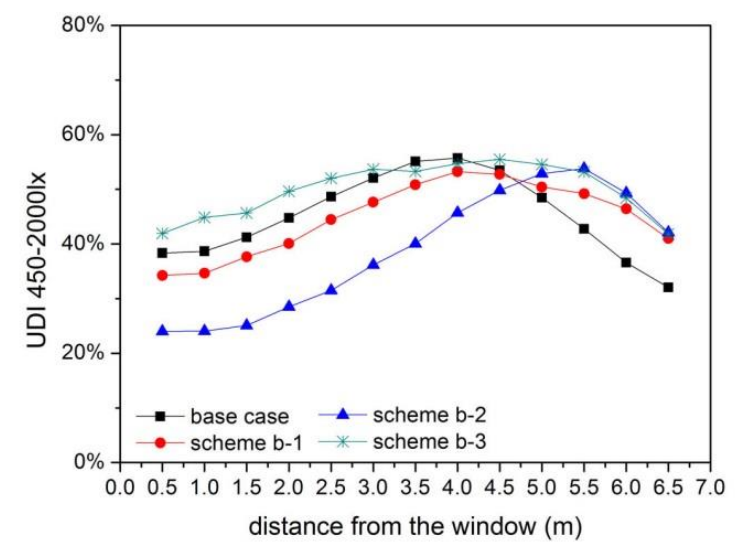

(e)

Figure 8. Average $\mathrm{UDI}_{450-2000 l x}$ for each row at equal distance from the windows for different strategies: (a) Lhasa; (b) Yinchuan; (c) Beijing; (d) Shanghai; and (e) Chongqing. 


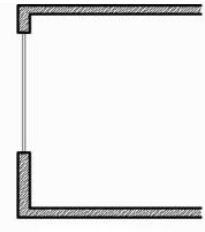

Basecase
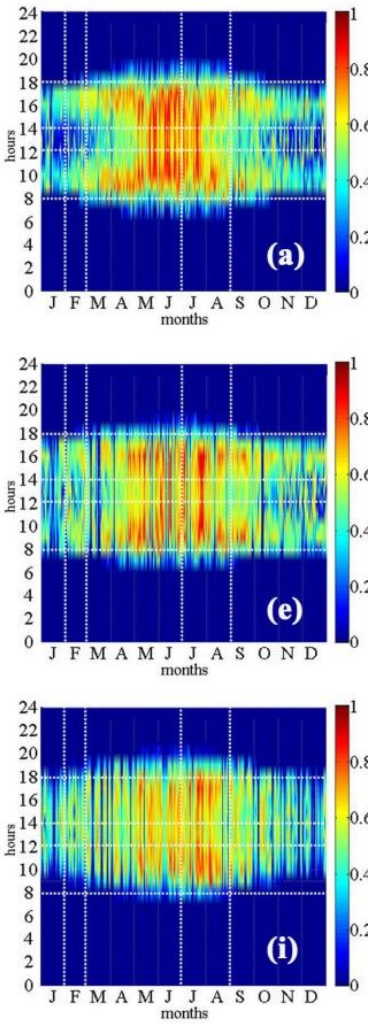
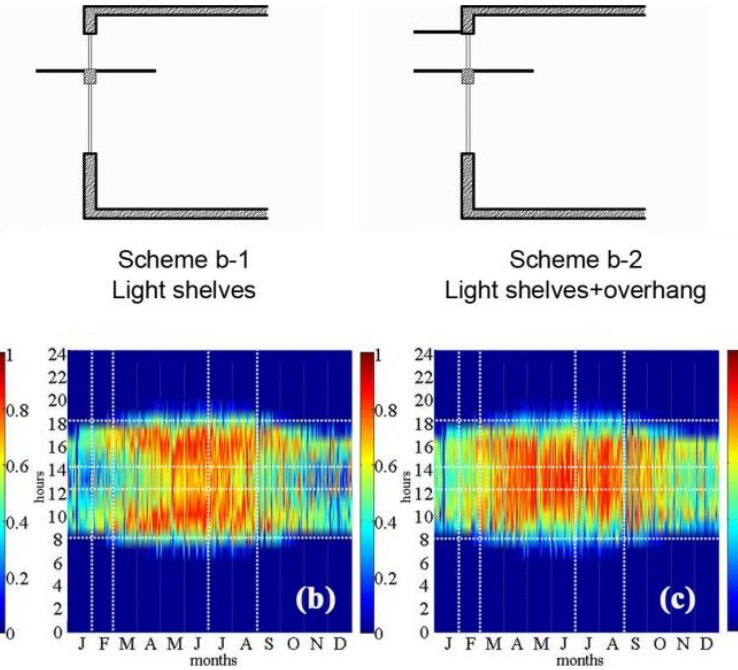

(c)
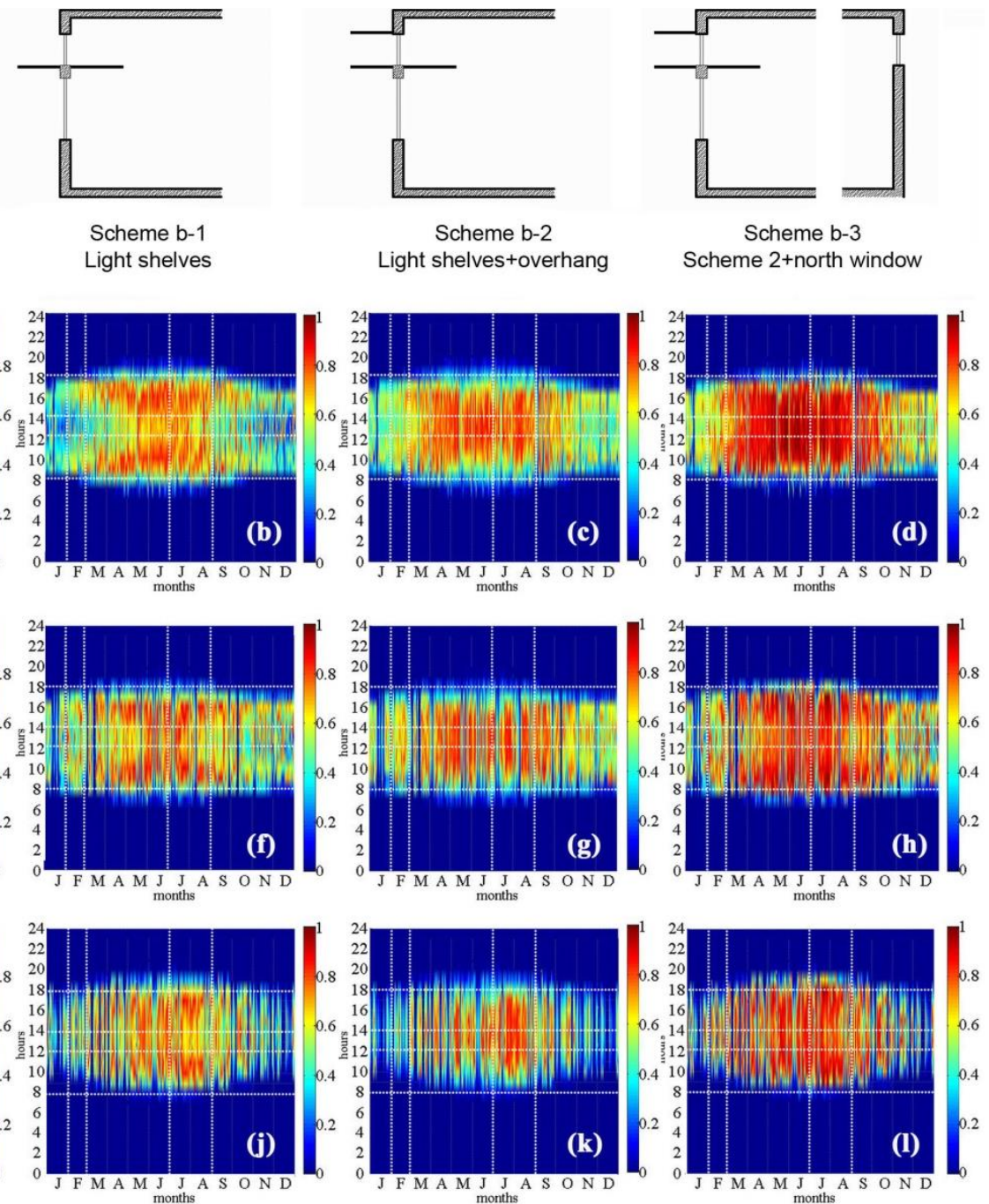

Figure 9. "In range" temporal maps of base classroom (a,e,i) and different strategies in Beijing (b-d), Shanghai (f-h) and Chongqing (j-l).

Besides the analysis of temporal map, curves of $\mathrm{UDI}_{450-20001 x}$ at equal distances from the window were also drawn for base case and optimal schemes of these three cities. As shown in Figure 8c-e, the curves of scheme b-3 in the three cities are all smoother than other schemes meaning it allows a more uniform and deeper penetration of good daylight.

Noteworthy, the "in range" temporal map of Chongqing is not as continuous as those of other cities. There were some navy blue lines across the whole year. It indicated constant low levels of interior illuminance all day long which related to the cloudy weather in Chongqing. The wider the blue line was, the longer time segment of cloudy days last. It can be seen that there were more navy blue lines in the segments of winter and spring, from about October to February, as these are the months with higher frequency of overcast skies. There were also some navy blue lines on the maps of Shanghai, although not as much as in Chongqing. It meant that for the cities in the light-climate region IV and V, even if a lighting strategy improved most of the annual time segments, the indoor lighting was still poor in the cloudy or rainy seasons. It is very important for these cities to pay attention to daylighting design to relieve the lighting deficiency and reduce the energy consumption of electrical lighting. 


\section{Discussion}

Utilization of daylight plays a crucial role in both the environment quality perceived by student and on the related energy savings. Using climate-based simulation, the daylighting characteristics of a typical classroom were evaluated under diverse conditions of five representative cities in China. These cities were selected from the five light-climate regions, which are termed I to $\mathrm{V}$, where the regions with higher number possess less daylight resource. With the aim of addressing different issues in the five cities, comparison of several daylighting design strategies was undertaken using intuitive temporal maps. Through this comparison, the most suitable design typology stood out for each of the five cities. The results and analysis method in this paper are useful for China, a country with an enormous amount of high-energy buildings, and may also serve as a reference to other similar study.

Temporal maps and goal-oriented metrics, two analysis tools adopted in this paper, made it feasible to achieve an excellent daylighting design taking into account the annual performance profile. The goal oriented map focused on the performance objectives the designer actually wants to reach. It offers the potential to format information in a way that directly makes sense for the project and for the designer without the intermediate step of interpreting the considered quantity itself. On the maps drawn with absolute value, one may not be able to distinguish the difference between $440 \mathrm{~lx}$ and $460 \mathrm{~lx}$ because they are quite similar in color. However, in the goal-oriented metrics, compared with the limitation of 450 lx, the 440 lx data would be drawn on the map of "too dark", while the 460 lx data on the map of "in range". Meanwhile, a temporal map displays the climate-based, time-variable data for the design process. They can reveal the nature of the environmental conditions in which a design performs well or poorly. They also encourage the designer to address the most important issues in daylighting design, such as increasing or reducing the daylighting quantity, with an annual perspective. With one glance on the temporal map, the designer could gain the annual variation which could help him to modify the design strategy according to seasonal or daily trends without drowning in data noise, and without having to rely on only a few static index during the year as in the past. In addition, based on the regular temporal maps, we proposed that more attention be paid on the message within occupancy time with the purpose of integrating daylighting design with human activity and thus achieve the optimal efficiency.

In addition to the analysis of temporal maps, the average values of $\mathrm{UDI}_{450-20001 \mathrm{x}}$ at different distances from the window were calculated for the comparison on daylighting homogeneity. The results showed that the scheme with higher spatial proportion achieving illuminance benchmark also performs better on the spatial distribution. The better performing strategies improve the daylighting distribution through decreasing the contrast between areas close to the window and in back of the room. Due to the time and financial limitations, further research relating to the visual comfort of occupant such as some glare indicators will be It will also include experimental verification which could enhance the reliability and practicability of current study.Besides, the window properties are closely related to the energy saving effects. conducted in our next study project. The normal double-pane window with clear glasses was investigated in this paper. More innovative materials should be considered in the further research, such as the monolithic aerogel glazed window [43], photovoltaic systems [46] and so on.

\section{Conclusions}

Based on the climate conditions of China, this paper compared different passive design strategies for five representative cities.The results showed that the climate difference is evident across the five light-climate regions in China. The frequencies of clear/overcast skies are distinct, for instance, a difference of over 10 times was observed between Lhasa and Chongqing (cities selected from the regions with richest and poorest daylight resource). On the evaluation of the indoor daylight quality, the proportion of spatial area achieving the desired illuminance range is higher in cities located in lower number light-climate region, such as Lhasa (Region I) and Yinchuan (Region II) . At the same time, these cities face higher glare risk thus shading devices should be the priority in daylighting design. 
The scheme a-2 of "light shelves + overhang", which can reduce the ratio of special area excessive desired range and make the lighting distribution more uniform, performs better than other strategies. For cities with higher light-climate number, such as Beijing (Region III), Shanghai (Region IV) and Chongqing (Region V), the proportion of spatial area reaching illuminance threshold is relatively lower and thus the inadequate light intensity becomes the main issue. The scheme b-3 of opening a new window on the north wall in addition to the southern "light shelves + overhang" achieved the best effect on spatial ratio above illuminance threshold and increased the homogeneity of daylight distribution. Although optimal strategies may improve the spatial ratio fulfilling the desired illuminance range to $50 \%-80 \%$, it must be noted that the daylight quality is inadequate in early morning and late afternoon and extra artificial lighting was needed during the first and last classes of the day. Since it is difficult to be bright enough when the sun is near horizon, the objective of this paper was to investigate the appropriate strategies to ensure the light quality in most occupancy time and to point out the time segments needing extra artificial lighting by temporal maps.

There are some limitations of this paper that need to be pointed out. For instance, only one orientation and one room size were evaluated and discussed in this paper. As the combination of daylight dynamic metrics and goal oriented evaluation was less applied to the daylighting design of educational enviroment in China, only a preliminary suggestion of design typology was given for the five representative cities. Detailed calculation could be performed to determine the exact size of the architectural device, such as the precise width or length of the light shelves or shading plate according to certain climate condition of a certain place. Further studies that include experimental verification, a greater number of metrics (such as glare probability metrics and dynamic thermal assessment [47]) and more samples with additional orientations, room size and climate conditions will improve the scope and application of our work.

Acknowledgments: This work was supported by National Natural Science Foundation of China (grant number 51178483, 51378518) and State Key Lab of Subtropical Building Science, South China University Of Technology (grant number 2016ZA02).

Author Contributions: Yonghong Yan. and Yang Guan conceived and designed the research framework; and Yang Guan performed the computer calculation and wrote the paper.

Conflicts of Interest: The authors declare no conflict of interest.

\section{References}

1. Petroleum, B. British Petroleum Statistical Review of World Energy; British Petroleum: London, UK, 2010.

2. International Energy Agency. $\mathrm{CO}_{2}$ emissions from fuel combustion; International Energy Agency: Paris, France, 2014.

3. International Energy Agency. Modernising Building Energy Codes; International Energy Agency: Paris, France, 2013.

4. International Energy Agency. Transition to Sustainable Buildings: Strategies and Opportunities to 2050; International Energy Agency: Paris, France, 2013.

5. Chen, X.; Yang, H.X. Combined thermal and daylight analysis of a typical public rental housing development to fulfil green building guidance in hong kong. Energy Build. 2015, 108, 420-432. [CrossRef]

6. Eliyahu, N.E. A comprehensive approach to the integration of daylight and electric light in buildings. Energy Build. 1984, 6, 78-108.

7. Dijk, D.J.; Lockley, S.W. Functional genomics of sleep and circadian rhythm-Invited review: Integration of human sleep-wake regulation and circadian rhythmicity. J. Appl. Physiol. 2002, 92, 852-862. [CrossRef] [PubMed]

8. Stevens, R.G.; Blask, D.E.; Brainard, G.C.; Hansen, J.; Lockley, S.W.; Provencio, I.; Rea, M.S.; Reinlib, L. Meeting report: The role of environmental lighting and circadian disruption in cancer and other diseases. Environ. Health Perspect. 2007, 115, 1357-1362. [CrossRef] [PubMed]

9. Mills, P.R.; Tomkins, S.C.; Schlangen, L.J.M. The effect of high correlated colour temperature office lighting on employee wellbeing and work performance. J. Circadian Rhythms 2007, 5, 2. [CrossRef] [PubMed] 
10. Juslen, H.; Wouters, M.; Tenner, A. The influence of controllable task-lighting on productivity: A field study in a factory. Appl. Ergon. 2007, 38, 39-44. [CrossRef] [PubMed]

11. Berardi, U. A cross-country comparison of the building energy consumptions and their trends. Resour. Conserv. Recycl. 2016, in press. [CrossRef]

12. National Bureau of Statistics of the People's Republic of China. China Statistical Yearbook, 2014; China Statistics Press: Beijing, China, 2015. (In Chinese)

13. Building Energy Research Center in Tsinghua Univiersity. 2015 Annual Report on China Building Energy Efficiency; China Achitecture \& Building Press: Beijing, China, 2015.

14. Ministry of Education of the People's Republic of China. Reports on National Students' Constitution and Health of People's Republic of China in 2010; Ministry of Education of the People's Republic of China: Beijing, China, 2011.

15. Ministry of Education of the People's Republic of China. Reports on National Students' Constitution and Health of People's Republic of China in 2005; Ministry of Education of the People's Republic of China: Beijing, China, 2006.

16. Ministry of Education of the People's Republic of China. Reports on National Students' Constitution and Health of People's Republic of China in 2000; Ministry of Education of the People's Republic of China: Beijing, China, 2001.

17. Wang, Y.; Ding, H.; Stell, W.K.; Liu, L.P.; Li, S.Q.; Liu, H.S.; Zhong, X.W. Exposure to sunlight reduces the risk of myopia in rhesus monkeys. PLoS ONE 2015, 10, 16. [CrossRef] [PubMed]

18. Hua, W.-J.; Jin, J.-X.; Wu, X.-Y.; Yang, J.-W.; Jiang, X.; Gao, G.-P.; Tao, F.-B. Elevated light levels in schools have a protective effect on myopia. Ophthalmic Physiol. Opt. 2015, 35, 252-262. [CrossRef] [PubMed]

19. Ministry of Housing and Urban-Rural Development of the People Republic of China. Gb5033-2013. Standard for Daylighting Design of Buildings; Ministry of Housing and Urban-Rural Development of the People Republic of China: Beijing, China, 2012. (In Chinese).

20. Huang, X.; Li, J.; Zhang, X.; Qian, X.; Wang, X.; Li, L.; Zhao, J.; Xu, D.; Liu, B.; Li, Q.; et al. Current situation of classroom lighting of primary and secondary schools in urban area of jilin province. Chin. J. Sch. Health 2014, 35, 628-630. (In Chinese)

21. Ruilan, Z.; Yutang, L. Investigation of public hygiene of primary and secondary schools in shunyi district, beijing city from 2008 to 2009. Chin. J. Health Insp. 2010, 17, 352-354.

22. Xiaoqin, C.; Jiafei, Y. Investigation and analysis of the luminous environment of some middle and primary school classrooms in chongqing. China Illum. Eng. J. 2011, 22, 25-30.

23. Reinhart, C.F.; Herkel, S. The simulation of annual daylight illuminance distributions-A state-of-the-art comparison of six radiance-based methods. Energy Build. 2000, 32, 167-187. [CrossRef]

24. Reinhart, C.F.; Walkenhorst, O. Validation of dynamic radiance-based daylight simulations for a test office with external blinds. Energy Build. 2001, 33, 683-697. [CrossRef]

25. Nabil, A.; Mardaljevic, J. Useful daylight illuminances: A replacement for daylight factors. Energy Build. 2006, 38, 905-913. [CrossRef]

26. Reinhart, C.F.; Jakubiec, J.A.; Ibarra, D. Definition of a Reference Office for Standardized Evaluations of Dynamic Facade and Lighting Technologies. In Proceedings of the BS 2013: 13th Conference of the International Building Performance Simulation Association, Chambery, France, 26-28 August 2013; pp. 3645-3652.

27. Glassman, E.J.; Reinhart, C. Facade Optimization Using Parametric Design and Future Climate Scenarios. In Proceedings of the BS 2013: 13th Conference of the International Building Performance Simulation Association, Chambery, France, 26-28 August 2013; pp. 1585-1592.

28. Berardi, U.; Wang, T. Daylighting in an atrium-type high performance house. Build. Environ. 2014, 76, 92-104. [CrossRef]

29. Shanyu, G.Z.L. Assessment of the anidolic lighting technology for inhabitant in high-rise and high-density surroundings. Archit. J. 2010, 3, 24-26.

30. Sun, C.; Lian, Z. Study on evaluatin method for illumination environment and energy consumption in office building. Archit. J. 2013, 2, 86-89.

31. Reinhart, C.F.; Wienold, J. The daylighting dashboard-A simulation-based design analysis for daylit spaces. Build. Environ. 2011, 46, 386-396. [CrossRef] 
32. Andersen, M.; Gagne, J.M.L.; Kleindienst, S. Interactive expert support for early stage full-year daylighting design: A user's perspective on lightsolve. Autom. Constr. 2013, 35, 338-352. [CrossRef]

33. Kleindienst, S.; Bodart, M.; Anderson, M. Graphical representation of climate-based daylight performance to support architectural design. Leukos 2008, 5, 39-61. [CrossRef]

34. Andersen, M.; Kleindienst, S.; Yi, L.; Lee, J.; Bodart, M.; Cutler, B. An intuitive daylighting performance analysis and optimization approach. Build. Res. Inf. 2008, 36, 593-607. [CrossRef]

35. Perez, R.; Ineichen, P.; Seals, R.; Michalsky, J.; Stewart, R. Modeling daylight availability and irradiance components from direct and global irradiance. Sol. Energy 1990, 44, 271-289. [CrossRef]

36. Zhang, Q.; Yang, H. Typical Meteorological Database Handbook for Buildings; China Achitecture \& Building Press: Beijing, China, 2012.

37. Kleindienst, S.; Andersen, M. Comprehensive annual daylight design through a goal-based approach. Build. Res. Inf. 2012, 40, 154-173. [CrossRef]

38. Nabil, A.; Mardaljevic, J. Useful daylight illuminance: A new paradigm for assessing daylight in buildings. Light. Res. Technol. 2005, 37, 41-59. [CrossRef]

39. Mardaljevic, J. Examples of climate-based daylight modelling. In Proceedings of the CIBSE National Conference 2006: Engineering the Future, London, UK, 21-22 March 2006.

40. Reinhart, C.F.; Mardaljevic, J.; Rogers, Z. Dynamic daylight performance metrics for sustainable building design. Leukos J. Illum. Eng. Soc. 2006, 3, 7-31.

41. Mardaljevic, J.; Andersen, M.; Roy, J.; Christoffersen, J. Daylighting metrics for residential buildings. Presented at the 27th Session of CIE, Sun City, South Africa, 11-15 July 2011.

42. Mardaljevic, J.; Andersen, M.; Roy, N. Daylighting metrics: Is there a relation between useful daylight illuminance and daylight glare probability? In Proceedings of the Building Simulation and Optimization Conference, Loughborough, UK, 10-12 September 2012; pp. 189-196.

43. Berardi, U. The development of a monolithic aerogel glazed window for an energy retrofitting project. Appl. Energy 2015, 154, 603-615. [CrossRef]

44. Cammarano, S.; Pellegrino, A.; Lo Verso, V.R.M.; Aghemo, C. Assessment of daylight in rooms with different architectural features. Build. Res. Inf. 2015, 43, 222-237. [CrossRef]

45. Berardi, U.; Anaraki, H.K. Analysis of the impacts of light shelves on the useful daylight illuminance in office buildings in toronto. Energy Procedia 2015, 78, 1793-1798. [CrossRef]

46. Presciutti, A.; Asdrubali, F. Sun simulators: Development of an innovative low cost film filter. Sustainability 2014, 6, 6830-6846. [CrossRef]

47. Alibaba, H. Determination of optimum window to external wall ratio for offices in a hot and humid climate. 2016, 8, 187. [CrossRef]

(C) 2016 by the authors; licensee MDPI, Basel, Switzerland. This article is an open access article distributed under the terms and conditions of the Creative Commons Attribution (CC-BY) license (http://creativecommons.org/licenses/by/4.0/). 